International Journal of Medical Anesthesiology 2021; 4(1): 131-133

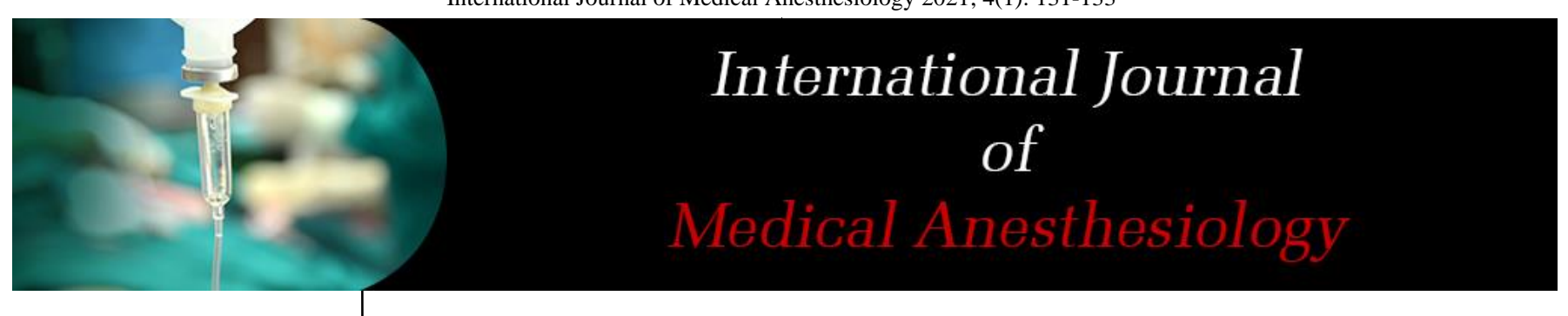

E-ISSN: 2664-3774

P-ISSN: 2664-3766

www.anesthesiologypaper.com

IJMA 2021; 4(1): 131-133

Received: 13-11-2020

Accepted: 19-12-2020

Dr. Sabyasachi Tripathy Assistant Professor, Department of Anaesthesia Hi-tech Medical College and Hospital, Pandra,

Bhubaneswar, Odisha, India

Dr. Dhiraj Prakash Senior Consultant, Department of Surgery, Autonomous State Medical College, Ghazipur,

Uttar Pradesh, India
Corresponding Author: Dr. Dhiraj Prakash Senior Consultant, Department of Surgery, Autonomous State Medical College, Ghazipur,

Uttar Pradesh, India

\section{A study to observe influence of general anesthesia on cognitive functions in patients of abdominal surgery}

\author{
Dr. Sabyasachi Tripathy and Dr. Dhiraj Prakash
}

DOI: https://doi.org/10.33545/26643766.2021.v4.i1b.278

\begin{abstract}
Background: As anesthesia is used routine basis on every surgery, it is required to assess the side effects of the anesthesia. Recent research has focused on the cognitive dysfunctions followed by general anesthesia.

Objectives: The present study was undertaken to observe the influence of general anesthesia on cognitive functions in patients of abdominal surgery.

Methods: The present study involved 40 patients of gastro intestinal surgery, within the age group of 20 to 60 years of age. Both the genders (males $=15$ ), Females $=25$ ) were included in the study Spatial and verbal memory was assessed using standard methods.

Results: Majority of the patients belongs to age group of 41-50 years. Same was observed in case of male population. But more females belong to age group of 30-40 years $(52 \%)$. There was significant decline in the spatial and verbal memory scores followed by the administration of anesthesia. The twotailed $\mathrm{P}$ value is less than 0.0001 for verbal memory. By conventional criteria, this difference is considered to be extremely statistically significant. The mean of Group One minus Group Two equals 3.00. 95\% confidence interval of this difference: From 2.30 to 3.70. The two-tailed $P$ value is less than 0.0001 for spatial memory. By conventional criteria, this difference is considered to be extremely statistically significant. The mean of Group One minus Group Two equals 3.00. 95\% confidence interval of this difference: From 2.55 to 3.45 .

Conclusion: There was significant decline in the cognition scores followed by administration of anesthesia. There is a need to study more in this area to understand the relationship between the two variables and also plan the proper management strategies.
\end{abstract}

Keywords: cognition, anesthesia, memory, surgery

\section{Introduction}

As anesthesia is used routine basis on every surgery, it is required to assess the side effects of the anesthesia ${ }^{[1]}$. Recent research has focused on the cognitive dysfunctions followed by general anesthesia ${ }^{[2]}$. It was reported that there is decline of neuro psychological functions followed by the administration of general anesthesia ${ }^{[3]}$. The first study in this area was reported in patients undergoing cardiac surgeries and later the concept was extended to other surgeries also ${ }^{[4]}$. Cardiac surgeries are more frequent to cause cognitive decline as there is decrease in the perfusion to the brain ${ }^{[5]}$. In recent years studies focused on assessment of the cognitive decline followed by the anesthesia administration ${ }^{[6-8]}$. Around sixty percentages of patients has decline in the cognitive functions after the surgery ${ }^{[9]}$. The decline was prominent after 7 days of the surgery ${ }^{[10]}$. The underlying mechanism is not clear yet. It was observed that there is a metabolic disturbance that causes cognitive decline or there may be direct effect of anesthesia. The present study was undertaken to observe the influence of general anesthesia on cognitive functions in patients of abdominal surgery.

Materials and methods

Study design: Observational study

Sampling method: Convenient sampling

Study population: The present study involved 40 patients of abdominal surgery, within the age group of 20 to 60 years of age. Both the genders (males =15), Females =25) were included in the study. Thorough clinical evaluation was conducted to all the patients. Patients undergoing laparoscopic cholecystectomy were included in the study. Voluntary informed 
consent was obtained from all the patients before the study. Willing participants, who are not having any severe complications, were included in the study. Unwilling patients with severe complications and any disorders of cognition and undergoing any psychological therapy were excluded from the study.

Method of data collection: Word recall and number recall methods were estimated using the standard methods in the literature. Patients were showed 10 words and 10 numbers in the screen for 2 minutes and one minute break is given and asked then to recall the numbers and words they have seen. Two minutes time is given to them to recall. The number of words and numbers they recall is considered as their spatial and verbal memory scores.

Ethical consideration: The study proposal was approved by an institutional human ethical committee. Informed consent was obtained from all the participants. Confidentiality of data was maintained.

Data analysis: Data was analyzed using SPSS 20.0 version. Demographic data was presented as frequency and percentage. Student t-test was used to assess the significance of the difference between the groups.

\section{Results}

Table 1 presents the age wise distribution of cases. Table 2 presents the age wise distribution of cases in male patients. Table 3 presents the age wise distribution of cases in female patients. Table 4 presents the pre and post-anesthesia cognition scores in patients. Majority of the patients belongs to age group of 41-50 years. Same was observed in case of male population. But more females belong to age group of $30-40$ years $(52 \%)$. There was significant decline in the spatial and verbal memory scores followed by the administration of anesthesia. The two-tailed $\mathrm{P}$ value is less than 0.0001 for verbal memory. By conventional criteria, this difference is considered to be extremely statistically significant. The mean of Group One minus Group Two equals 3.00. 95\% confidence interval of this difference: From 2.30 to 3.70. The two-tailed $\mathrm{P}$ value is less than 0.0001 for spatial memory. By conventional criteria, this difference is considered to be extremely statistically significant. The mean of Group One minus Group Two equals 3.00 . $95 \%$ confidence interval of this difference: From 2.55 to 3.45 .

Table 1: Age wise distribution of cases.

\begin{tabular}{|c|c|c|}
\hline Age group in years & Number of patients $(\mathbf{n}=\mathbf{4 0})$ & percentage \\
\hline$<30$ & 2 & 5 \\
\hline $30-40$ & 16 & 40 \\
\hline $41-50$ & 20 & 50 \\
\hline $51-60$ & 2 & 5 \\
\hline
\end{tabular}

Data was presented as frequency and percentage

Table 2: Age wise distribution of cases in male patients

\begin{tabular}{|c|c|c|}
\hline Disease & Number of patients $(\mathbf{n}=15)$ & percentage \\
\hline$<30$ & 2 & 13.33 \\
\hline $30-40$ & 3 & 20 \\
\hline $41-50$ & 8 & 53.33 \\
\hline $51-60$ & 2 & 13.33 \\
\hline
\end{tabular}

Data was presented as frequency and percentage

Table 3: Age wise distribution of cases in female patients

\begin{tabular}{|c|c|c|}
\hline Disease & Number of patients $(\mathbf{n = 2 5})$ & percentage \\
\hline$<30$ & 0 & 0 \\
\hline $30-40$ & 13 & 52 \\
\hline $41-50$ & 12 & 48 \\
\hline $51-60$ & 0 & 0 \\
\hline
\end{tabular}

Data was presented as frequency and percentage

Table 4: Pre and post-anesthesia cognition scores in patients

\begin{tabular}{|c|c|c|c|}
\hline Bilirubin & Pre anesthesia $(\mathbf{n}=\mathbf{4 0})$ & Post-anesthesia $(\mathbf{n}=\mathbf{4 0})$ & P value \\
\hline Verbal memory & $6 \pm 0.32$ & $3 \pm 0.16$ & $<0.0001 * * *$ \\
\hline Spatial memory & $7 \pm 0.16$ & $4 \pm 0.16$ & $<0.0001 * * *$ \\
\hline
\end{tabular}

Data was presented as Mean and SEM. ( $* * * P<0.001$ is significant)

\section{Discussion}

Cognition is most important aspect of life. Cognitive functions include learning, memory, reaction time etc. These functions are associated with day to day activities and help to maintain quality of life. That is the reason why cognitive functions are so important to assess. Decline in cognition will decline the quality of life. The studies related to administration of anesthesia and cognition is sparse. The present study was undertaken to observe the influence of general anesthesia on cognitive functions in patients of abdominal surgery. Majority of the patients belongs to age group of 41-50 years. Same was observed in case of male population. But more females belong to age group of 30-40 years $(52 \%)$. There was significant decline in the spatial and verbal memory scores followed by the administration of anesthesia.

Earlier studies explained that there is decline in the cognitive activities followed by the administration of anesthesia. Few studies explained that the reason for decline in the cognition may be due to interruption of blood supply to brain. Interestingly other studies explained that there may be change in the metabolism that contributes to decline in cognition. Another concept is that there may be inhibition of neuronal transmission that decreases the transmission of impulses and decline the cognition. This is especially true if the neurons involved are cholinergic neurons. Another interesting study explained that after administration of anesthesia there will be increase in the prevalence of brain diseases like Alzheimer's diseases which is mainly associated with cognitive functions. However, being a study conducted at one center, our study cannot lay out any recommendations or can draw generalizations. Further detailed studies are mandatory to suggest avoiding general anesthesia except in cases of mandatory.

\section{Conclusion}

There was significant decline in the cognition scores followed by administration of anesthesia. There is a need to study more in this area to understand the relationship between the two variables and also plan the proper management strategies. 


\section{References}

1. Newman S, Jan S, Shashivadan H et al. Postoperative Cognitive Dysfunction after Noncardiac Surgery. Anesthesiology 2007;106(3):572590.

2. Hanning CD. Postoperative cognitive dysfunction. Br J Anaesth 2005;95(1):82-87.

3. Gao L, Taha R, Gauvin D et al. Postoperative cognitive dysfunction after cardiac surgery. Chest 2005;128(5):3664-3670.

4. Johnson T, Monk T, Rasmussen LS et al. Postoperative cognitive dysfunction in middle-aged patients. Anesthesiology 2002;96(6):1351-1357.

5. Monk TG, Weldon BC, Garvan CW et al. Predictors of Cognitive Dysfunction after Major Non cardiac Surgery. Anesthesiology 2008;108(1):18-30.

6. Moller JT, Cluitmans P, Rasmussen LS et al. Longterm postoperative cognitive dysfunction in the elderly: ISPSOCD1 study. Lancet 1998;351:857-861.

7. Rasmussen LS, O'Brien JT, Silverstein JH et al. Is perioperative cortisol secretion related to post-operative cognitive dysfunction? Acta Anaesthesiol Scand 2005;49(9):1225-1231.

8. Canet J, Raeder J, Rasmussen LS et al. Cognitive dysfunction after minor surgery in the elderly. Acta Anaesthesiol Scand 2003;47(10):1204-1210.

9. Rosemeier F, Avidan M, Kurz A et al. Postoperative cognitive dysfunction: over interpretation of data? Anesthesiology 2003;98(5):1294-1295.

10. Rasmussen LS, Johnson T, Kuipers HM et al. Does anaesthesia cause postoperative cognitive dysfunction? A randomised study of regional versus general anaesthesia in 438 elderly patients. Acta Anaesthesiol Scand 2003;47(3):260-266.

11. Steinmetz J, Christensen KB, Lund T et al. Long-term consequences of postoperative cognitive dysfunction. Anesthesiology 2009;110(3):548-555.

12. Borde N, Jaffard R, Beracochea D. Effects of chronic alcohol consumption or diazepam administration on item recognition and temporal ordering in a spatial working memory task in mice. Eur $\mathrm{J}$ Neurosci 1998;10:2380-7.

13. Porter MC, Mair RG. The effects of frontal cortical lesions on remembering depend on the procedural demands of tasks performed in the radial arm maze. Behav Brain Res 1997;87:115-25.

14. Ward MT, Stoelzel CR, Markus EJ. Hippocampal dysfunction during aging II: deficits on the radial-arm maze. Neurobiol Aging 1999;20:373-80.

15. Bailey JM. Context-sensitive half-times and other decrement times of inhaled anesthetics. Anesth Analg 1997;85:681-6.

16. Olton DS, Samuelson RJ. Remembrance of places passed: Spatial memory in rats. J Exp Psychol Anim Behav Process 1976;2:97-116.

17. Bailey CH, Bartsch D, Kandel ER. Toward a molecular definition of long-term memory storage. Proc Natl Acad Sci USA 1996;93:13445-52.

18. Levin ED, Uemura E, Bowman RE. Neurobehavioral toxicology of halothane in rats. Neurotoxicol Teratol 1991;13:461-70. 